\title{
Os Sentidos de Compreensão nas Teorias de Weber E Habermas
}

\author{
José Geraldo A. B. Poker ${ }^{1}$
}

\begin{abstract}
RESUMO: Partindo do pressuposto de que a teoria social elaborada por Habermas em muito se assemelha àquela construída por $\mathrm{M}$. Weber, procedeu-se a um estudo comparativo com a intençấo de identificar as formas pelas quais Weber e Habermas elaboraram o conceito de compreensão, ao mesmo tempo em que e o elegeram, cada um a seu modo, como instrumento metodológico adequado às dificuldades da produção de conhecimento científico nas Ciências Sociais. Tanto para Weber, como para Habermas, o conhecimento nas Ciências Sociais não consegue escapar das influências diretas da subjetividade do cientista, como também não é capaz de se proteger das contingências históricoculturais aos quais inevitavelmente toda açâo humana está vinculada. Por isso, fundamentados em suas próprias razóes, tanto Weber quanto Habermas apontam a compreensão como a forma possível de conhecimento, o que implica a renúncia às pretensôes explicativas e à produção de teorias gerais de fundamentação última, que são típicas das ciências convencionais.
\end{abstract}

PALAVRAS-CHAVE: Compreensão. Explicação. Ciências Sociais. Habermas. Weber.

São diversas e bastante conhecidas as intersecções entre as teorias sociais elaboradas respectivamente por Max Weber e J. Habermas. No campo das Ciências Sociais e da Filosofia, há várias obras produzidas a respeito das formas pelas quais Habermas foi influenciado ou tomou emprestado aspectos pontuais da sociologia weberiana. Sobre isso, há que se mencionar também os muitos momentos em que Habermas elegeu Weber como seu interlocutor privilegiado, com quem estabeleceu diálogos intensos, a pretexto de demarcar as próprias concepçôes, como é o caso da teoria da modernidade ou da condição do Direito na sociedade ocidental moderna, apenas para citar alguns exemplos.

\footnotetext{
${ }^{1}$ Doutor em Sociologia pela FFLCH-USP. Professor Assistente-Doutor do Departamento de Sociologia e Antropologia da FFC-UNESP.
} 
No entanto, a despeito de essa primeira apresentaçáo parecer ser suficiente para localizar o leitor quanto ao que pode esperar, sente-se a necessidade de se tentar explicitar um tanto mais a razão que fundamentou a escolha desse assunto para ser aqui enfocado.

Em relação ao que foi afirmado de início, deve-se acrescentar que o conceito de compreensão e a maneira pela qual tal conceito foi transformado em instrumento metodológico nas Ciências Sociais, nas teorias de Weber e Habermas, constituem algo pouco tratado. Talvez a razão disso possa residir na pouca disposiçấo demonstrada pelas produçóes atuais nas Ciências Sociais em se debruçar na reflexão sobre os fundamentos epistemológicos sobre os quais se constrói o conhecimento típico da área.

O contexto do mundo globalizado e os problemas sociais dele decorrentes, sobretudo aqueles derivados da diversidade cultural em convivência nas novas formas de sociedade, parecem ter oferecido às Ciências Sociais um estoque temático e ao mesmo tempo uma utilidade prática completamente ausentes, em momentos históricos anteriores. Em consequência, a concretude dos novos objetos de estudo permitiram ao conhecimento produzido pelas Ciências Sociais encontrar uma condição de conforto. Durante décadas, tornou-se comum aludir a uma chamada crise nas Ciências Sociais, em parte causada por fatores como a falta de credibilidade científica da produção de conhecimento, a falta de criatividade dos cientistas sociais em identificar temas de estudo relevantes para a época, ou ainda pela dificuldade em conseguir isolar o conhecimento científico sobre os problemas sociais do debate ideológico em torno da hegemonia bipolar, que tomou conta de todo o planeta, até o final da década de 1990 .

Naquele tempo, a legitimidade para as Ciências Sociais somente era obtida a duras penas por meio do recurso à argumentação eminentemente filosófica, com o que se pretendia validar náo apenas o produto do conhecimento, mas ao mesmo tempo estabelecer as condições de validade da própria ciência que se propunha analisar os fatos do mundo social empiricamente produzidos, e que não eram propositadamente inventados por alguém para reforçar argumentos favoráveis ou contrários às duas ordens em disputa, o capitalismo e o socialismo.

Muito embora seja esse assunto muito importante, o que se pretende aqui não é refletir sobre a produção das Ciências Sociais, no período 19451990. A evocação desse contexto se dá a pretexto de justificar a necessidade 
do retorno às reflexôes epistemológicas nas Ciências Sociais, ainda que as circunstâncias da produção do conhecimento sobre o mundo social tenham mudado significativamente, em meio às quais o cientista social possa se sentir desobrigado de dedicar-se a elaborar justificativas para o conhecimento que produz sobre determinado fato da ordem da vida humana.

$\mathrm{O}$ ato de avaliar a contingência da falibilidade inerente a todo saber humano marca a disposiçáo inicial de um conhecimento que se pretende crítico sobre algo no mundo. Os riscos de conhecimentos que dispensam o exame sobre as condiçôes da própria validade são muitos, e aumentam demasiadamente, quando se trata de conhecimentos que se pretendem científicos acerca de fenômenos humanos. Quanto aos conhecimentos derivados da produção nas Ciências Sociais, eles podem ser instrumentalizados de diversas maneiras, e não raro se tornam bases para subsidiar e legitimar a elaboração e execução de políticas públicas ou para consubstanciar estratégias educacionais, apenas para citar alguns dos seus riscos.

Esta é, portanto, a justificativa da presente reflexão, e com a qual se espera demonstrar a necessidade de se refletir sobre os parâmetros com os quais se pode avaliar a produçáo do conhecimento do cientista social, com a intenção de evitar os erros comuns resultantes da ausência de crítica, dos quais o mimetismo e o dogmatismo são os mais graves e frequentes. Por mimetismo deve ser entendida a prática de imitação de conceitos, especialmente a utilização de vocábulos retirados dos modismos que afetam as Ciências Sociais, sem o cuidado de examinar a possibilidade de que tais vocábulos definam fatos para além do contexto em que foram originalmente empregados. Por dogmatismo deve ser entendida a prática de pré-definir os fenômenos da realidade social por meio da repetiçáo de teorias que tomam a forma de leis gerais para a vida em sociedade.

Em ambos os casos, o cientista pode errar ao desconsiderar outros fundamentos da crítica na pesquisa social. São aqueles que se referem à história e à singularidade dos fenômenos sociais, cuja existência está condicionada às formas próprias pelas quais determinadas pessoas produzem e reproduzem suas condiçôes de convivência, num determinado tempo, num determinado lugar, sob determinadas circunstâncias. 


\section{1 - A compreensão na teoria de Max Weber}

Inicialmente, parte-se do pressuposto de que a expressão compreensão não deve ser entendida apenas como uma palavra-chave na fundamentação metodológica, mas sobretudo precisa ser tratada como condição de um fundamento heurístico, isto é, como um conceito o qual perpassa transversalmente toda a extensão da teoria elaborada por Max Weber, porque, no conceito de compreensão, Weber exprime as características marcantes do conhecimento nas Ciências Sociais, que sinteticamente podem ser vislumbradas nos limites e possibilidades que cercam as tentativas de tematização racional da irracionalidade da cultura por alguém dedicado a esforçar-se por procurar os melhores meios de atribuir objetividade às escolhas derivadas da própria subjetividade, enquanto ator social e histórico, também inserido numa sociedade, numa cultura.

Não bastasse isso, a compreensão encerra em si a crítica de Weber à instrumentalização política das ciências humanas, defendida pelos positivistas, a complicada relação das ciências sociais com o modelo nomológico das ciências naturais, a divisão do trabalho entre a História e as ciências da cultura, e as muitas objeçôes dirigidas abertamente ao materialismo marxista. Enfim, é no conceito de compreensão que melhor se pode observar a complexa arquitetura intelectual criada por Weber para abrigar elementos retirados dos sistemas filosóficos de Kant e Nietzsche, e conciliá-los de modo a compor sua metodologia e identificar as condiçóes de falibilidade do próprio conhecimento.

Para justificar esse enunciado, recorre-se às obras dedicadas por Weber a explicitar certas nuances do processo intelectual de constituição da epistemologia por ele empregada para definir e abordar o objeto, a qual se constitui na criação dos tipos ideais, seguida da forma de apropriação e a delimitação do campo de conhecimento daquilo que ele mesmo definiria como ciências sociais, ciência da cultura ou, ainda, como sociologia.

Algumas das obras de Weber poderiam se prestar a essa finalidade. No entanto, dentre elas, escolheram-se as obras Ensaios sobre a teoria das Ciências Sociais (2008) e Conceitos Básicos de Sociologia (2008), por ser nelas que o autor se empenha em uma reflexáo aprofundada sobre a natureza, o problema e a extensão do conhecimento do real social.

Em Conceitos Básicos de Sociologia, a compreensão encontra-se vinculada ao próprio objetivo da sociologia, que, para Weber, "[...] tem como meta a compreensão interpretativa da ação social de maneira a obter uma explicação 
de suas causas, de seu curso e de seus efeitos" (WEBER, 2008a, p. 11). A primeira definição de compreensão implica o esforço do cientista em interpretar, e isso quer dizer identificar as bases lógicas e inteligíveis com as quais um ator social constrói o raciocínio com que ele mesmo explica as suas intenções na ação.

De pronto, ainda há que se notar a distinção entre compreensão e explicação. Trata-se, em primeiro plano, do esforço pela manutenção da condição de autenticidade na captura da subjetividade individual do ator social pelo cientista, que consiste na única possibilidade de ele ter acesso ao conjunto de significaçôes e valoraçôes que compóem qualquer cultura e que, em última instância, são os causadores de todos os fenômenos humanos. Este é então um dos limites da Sociologia: cabe a ela restringir-se a produzir um conhecimento das açóes sociais, dos aspectos da conduta humana inteligível, "[...] cujos sujeitos vinculem a esta ação um sentido subjetivo" (WEBER, 2008a, p. 11) e, por isso, conseguem eles mesmos explicar suas escolhas.

Neste ponto, há que se abrir um parêntese para considerar um ponto importante na perspectiva weberiana sobre a subjetividade. $\mathrm{O}$ âmbito subjetivo da conduta para Weber se refere não somente às formas pelas quais um sujeito social se constitui por intermédio do sistema simbólico específico de toda cultura. Refere-se também às formas pelas quais um sujeito empiricamente existente recorre à cultura para interpretar e atuar frente a outros sujeitos em contextos de relaçôes sociais historicamente singulares e determinados. A subjetividade da ação, na perspectiva de Weber, acarreta a dupla e simultânea condição da ação social: ela é ao mesmo tempo uma possibilidade do contexto histórico do ator, combinada com a forma própria pela qual um ator social entende e interpreta seu próprio contexto, empregando para tanto a mediação da cultura que constitui seu modo de ser, a sua objetividade.

A tentativa da explicação pelo cientista é secundária, e somente pode ser levada adiante por ele com a devida precaução de que o objeto do seu conhecimento permanece autêntico, isto é, a autenticidade do sentido subjetivo da ação de um ator social. A explicação estaria dessa forma associada a alguma tentativa de atribuição, ao exercício específico da capacidade do cientista, em poder ou não relacionar a existência de um caso particular à probabilidade de que venha ele ser a manifestação individualizada de um determinado fenômeno de ocorrência regular, sob determinadas condiçóes. 
Segundo Weber, na condição de uma interpretaçâo das açóes sociais, a compreensão pode ocorrer de formas variadas, sendo motivada inclusive por fatores de ordem empática, quer dizer, pela igual condição de vinculação a um mesmo conjunto valorativo.

Todavia, a compreensão empática contém os limites impostos pela dependência à igual vinculação a certos valores. Nesse caso, as ações não precisam ser explicadas pelos atores; o sentido delas pode ser automaticamente compreendido na extensão do seu significado, mas tal interpretação se encontra condicionada ao grau de compartilhamento dos valores que envolve o observador e o participante.

Existem ainda dois tipos de possibilidade de compreensão citados por Weber. Há a compreensão decorrente da participação numa mesma situação de ação, o que consiste na compreensão observacional, conseguida mediante a

[...] compreensão direta empírica do significado de um dado ato (inclusive um pronunciamento verbal). É neste sentido que "compreendemos" (isto é, diretamente) o significado da proposição de que $2 \times 2=4$, quando o ouvimos ou lemos. Experimentamos aqui a compreensão direta, racional de uma idéia. Da mesma maneira, compreendemos um acesso de raiva expressada por reclamações, expressão facial ou movimentos irracionais. Trata-se de compreensão direta empírica de reaçóes emocionais irracionais e pertence à mesma categoria que a observação da ação de um cortador de madeira, ou alguém que estende a mão para fechar a porta, ou que aponta uma arma a um animal. Trata-se de observação empírica racional do comportamento. (WEBER, 2008a, p. 17).

Uma outra forma de compreensão é aquela designada como compreensão explicativa. Sobre isso, afirma Weber:

Somos capazes de entender os motivos de qualquer um que afirma que $2 \times 2=4$ (oralmente ou por escrito) precisamente num momento particular e sob uma série determinada de circunstâncias. Tal compreensão pode ser obtida se a pessoa sob observação está empenhada em alguma tarefa de contabilidade ou alguma demonstraçáo científica ou algum outro projeto do qual esta tarefa é uma parte essencial. Trata-se da compreensão racionalmente baseada da motivação, isto é, o ato visto como parte de uma situação inteligível. (WEBER, 2008a, p. 17). 
Essas definiçốes preliminares por si mesmas permitem notar que a compreensão contém o entendimento de Weber a respeito do conhecimento sobre a ocorrência dos fenômenos humanos. Seriam todos eles derivados da subjetividade individual, das muitas formas pelas quais as subjetividades são compartilhadas por indivíduos para conformar as situações específicas de ordenamento social observáveis na história da humanidade. Como possibilidade de conhecimento científico e, portanto, objetivo, a sociologia somente se sustenta epistemologicamente à medida que consegue penetrar no intrincado complexo de construçóes valorativas sobre as quais as açóes sociais podem ser referidas. Por conseguinte, para Weber (2008a, p.18) a sociologia, "[...] uma ciência que trata do verdadeiro significado da ação, a explicação requer uma apreensão da conexão de sentido dentro do qual ocorre o curso da ação real"

Para além desses aspectos acima tratados, a extensão do sentido de compreensáo pode ser verificada no artigo intitulado $A$ objetividade do conhecimento nas ciências e politicas sociais, escrito por Weber, em 1904, como sistematização na escolha de publicações para a revista Archiv für Sozialwissenschaft und Sozialpolitik, da qual passou a compor o comitê de redação. Ao longo de várias páginas, nas quais Weber indica a forma desejada para os artigos enviados à revista, o conceito de compreensáo é abrangido pelo conceito de objetividade, que, por sua vez, se encontra vinculado à designação da condição do cientista, a sua competência, os limites do conhecimento a que ele se dedica e, ainda, as fronteiras que demarcam a finalidade ou a utilidade prática do conhecimento resultante da ciência social.

Nessa obra, a recomendação de Weber insiste sempre na delimitação do conhecimento da ciência do social, que deve ater-se à compreensão de um quadro valorativo. A compreensão significa o cuidado do cientista para não incorrer no erro de ajuizar sobre os valores envolvidos na ação individual. Nesse sentido, cabe à ciência social oferecer aos atores sociais um conhecimento acerca das consequências das escolhas e das suas implicaçóes, no campo valorativo, contribuindo para a racionalização na tomada de decisôes. Não cabe à ciência social propor a forma correta da ação ou qual seria a ação certa, num dado contexto. Da mesma forma, lembrando a famosa advertência de Weber, em Ciência e Política: duas vocaçóes, o cientista social, enquanto cientista, não possui qualquer garantia a propósito da certificação dos conselhos que porventura venha a oferecer a atores políticos. Tudo isso pode ser bem observado no trecho destacado a seguir: 
Ao estabelecer este fim, a crítica pode ajudar a pessoa dotada de vontade a refletir sobre os axiomas últimos em que se baseia o conteúdo de sua vontade, e sobre os padróes de valor, dos quais parte inconscientemente, ou deveria partir para ser conseqüente.

Auxiliar o indivíduo a tomar consciência desses padrōes últimos, que se manifestam no juízo de valor concreto, é o máximo que a crítica pode realizar sem entrar no campo da especulação. A questáo de "dever" o sujeito que ajuíza aceitar estes padrôes últimos é muito pessoal e apenas depende do seu querer e da sua consciência, e de modo algum do saber empírico.

Uma ciência empírica não está apta a ensinar a ninguém aquilo que "deve", mas sim e apenas o que "pode", e, em certas circunstâncias, que "quer" fazer. (WEBER, 2008b, p. 7, aspas e grifos do autor).

A preocupação com a objetividade encontra-se mais uma vez vinculada à condição da compreensão, à medida que o cientista social reconhece a especificidade dos fenômenos que se propóe conhecer e, dessa maneira, renuncia à pretensão de formular leis gerais mediante as quais poderia ele deduzir os fenômenos sociais. As leis e os conceitos que podem ser produzidos por meio do trabalho do cientista social não deverão consistir na finalidade da ciência. Antes de tudo, ressalta Weber, as teorias e tudo o mais que se refira às generalizaçóes sobre fenômenos devem ser produzidas e utilizadas apenas como meios no processo de compreensão dos condicionamentos subjetivos da ação social em situaçóes determinadas.

A produção de conceitos, de leis e de teorias teria de respeitar os limites da forma própria de produção de conhecimentos objetivos sobre os fenômenos sociais, e a dificuldade de generalizar acerca de possíveis causas para eles. Se algumas conexóes causais podem ser identificadas para explicar certos fenômenos no real social, tais conexốes devem ser admitidas como válidas para o conhecimento de uma sociedade determinada, aquela para a qual a explicação foi produzida, e não teria qualquer alcance universal, portanto.

Isso porque, na concepção de Weber, a realidade social é um objeto demasiadamente complexo em sua existência, podendo apenas ser parcialmente apreendido pela tentativa de interpretação dos sentidos das açóes e de suas significaçôes no espectro valorativo. Da renúncia à explicação e, pois, à formulação das leis gerais como fim da ciência social, chega-se à desistência necessária do cientista em pretender construir conhecimentos na forma de 
grandes teorias, que abranjam a totalidade da vida social num único sistema explicativo. Nesse aspecto, enfatiza Weber:

\begin{abstract}
Aspiramos ao conhecimento de um fenômeno histórico, isto é, significativo na sua singularidade. E o que aqui existe de decisivo é o fato de só adquirir sentido lógico a idéia de um conhecimento dos fenômenos individuais mediante a premissa de que possuirá uma significação. Inclusive, com o mais amplo conhecimento de todas as "leis" do devir, ficaríamos perplexos ante o problema de como é possível em geral a explicação causal de um fato individual, posto que nem sequer se pode pensar, de modo exaustivo, a mera descrição do mais ínfimo fragmento da realidade. Pois o número e a natureza das causas que determinaram qualquer acontecimento individual são sempre infinitos, e não existe nas próprias coisas critério algum que permita escolher de entre elas uma fração que possa entrar isoladamente em linha de conta. (WEBER, 2008b, p.36, grifos do autor)
\end{abstract}

Ao que se deve acrescentar:

Quando se trata da individualidade de um fenômeno, o problema da causalidade não incide sobre as leis, mas sobre conexóes causais concretas; não se trata de saber se a fórmula se deve subordinar o fenômeno a título de exemplar, mas sim a que constelação deve ser imputado o resultado. Trata-se, portanto, de um problema de imputação. Onde quer que se trate da explicação causal de um "fenômeno cultural" - ou ainda de uma "individualidade histórica", expressão já utilizada relativamente à metodologia da nossa disciplina, e agora habitual na lógica, com uma formulação mais precisa - , o conhecimento das leis da causalidade não poderá constituir o fim mas antes o meio do estudo. (WEBER, 2008b, p. 37 , aspas e grifos do autor).

Resignação quanto à renúncia de julgar valores na ação, à formulação de leis gerais e à elaboraçáo de grandes teorias sobre a vida social. O quadro das contençóes do conhecimento sociológico mediante a chave da compreensáo dos aspectos subjetivos da ação ainda precisa ser acrescido da condição de falibilidade inerente a essa forma de conhecimento. Sobre isso, Weber adverte o cientista social a respeito de que ele também se constitui como ator social e está terminantemente submetido a valores e a tudo o quanto de irracional eles contêm, tão submetido quanto os sujeitos e as açóes a que o cientista se dedica a estudar. Sobre isso, afirma Weber:

De tudo o que se disse até aqui resulta que carece de razão de ser um estudo "objetivo" dos acontecimentos culturais, no sentido em que o fim ideal do 
trabalho científico deveria consistir numa redução da realidade empírica a certas leis. Ora carece de razão de ser, náo porque - como muitas vezes se disse - os acontecimentos culturais ou, se se quiser, os fenômenos mentais evoluam "objetivamente" com menor regularidade, mas:

a) porque o conhecimento de leis sociais não é um conhecimento do socialmente real, mas unicamente um dos diversos meios auxiliares que o nosso pensamento utiliza para esse efeito; e

b) porque nenhum conhecimento dos acontecimentos cultuais poderá ser imaginado de outro modo que não seja com base na significação que para nós a realidade da vida, sempre estruturada de modo singular, possui em determinadas relaçóes singulares. (WEBER, 2008b, p. 39. grifos e aspas do autor).

\section{Ao que segue:}

[...] Daqui resulta que todo o conhecimento da realidade cultural é sempre um conhecimento subordinado a pontos de vista especificamente particulares. Quando exigimos do historiador ou do sociólogo a premissa elementar de saber distinguir entre o essencial e o secundário, de possuir para esse fim os "pontos de vista" necessários, queremos unicamente dizer que ele deverá saber referir - consciente ou inconscientemente - os elementos da realidade a "valores culturais universais" e selecionar consequentemente as conexôes que para nós se revistam de significado. [...] A propósito desta seleção de "aspectos" especiais e individuais do devir, que sempre e em todos os casos se realiza consciente ou inconscientemente, reina também essa concepção do trabalho científico-cultural que constitui a base da tão repetida afirmação de que o elemento "pessoal" é o que verdadeiramente confere valor a uma obra científica. Ou seja, de que qualquer obra deveria exprimir uma "personalidade" paralelamente a outras qualidades. (WEBER, 2008b, p. 40, grifos e aspas do autor).

\section{2 - A COMPREENSÁo NA TEORIA DE HabermaS}

Para efeitos da análise aqui pretendida, tomaram-se como base as reflexões e demonstrações elaboradas por Habermas e contidas em duas de suas muitas obras conhecidas. Uma delas é o pequeno texto Ciências Sociais reconstrutivas versus ciências sociais compreensivas (doravante CSRCSC), escrito em 1980 e publicado na coletânea de artigos intitulada Consciência moral e agir comunicativo (Rio de Janeiro: Tempo Brasileiro, 1987). A outra obra utilizada foi $A$ lógica das Ciências Sociais (doravante LCS), publicada originalmente em 
1982, na Alemanha, mas que reúne textos escritos pelo autor desde o final da década de 1960. No entanto, somente em 2009 essa obra foi traduzida e publicada no Brasil (2009).

A escolha dessas duas obras, em meio a tantas outras que poderiam ser igualmente estudadas, deveu-se primeiramente ao fato de serem textos que tratam da problemática da compreensão nas ciências sociais e que se referem mutuamente, apesar da distância temporal que as separa. E, embora Habermas estabeleça diálogos com Weber, em muitos de seus trabalhos, é nessas duas obras que o diálogo se realiza em torno de perspectivas metodológicas.

Além disso, há duas características marcantes nas obras, que em muito contribuíram na tentativa de analisar a concepção habermasiana de compreensão, a fim de compará-la com aquela elaborada por Weber. Sobre tais características, há que se destacar o fato de que, em LCS, Habermas dedicou-se exaustivamente a demonstrar as formas pelas quais a interpretação se constitui numa condicionante inerente ao conhecimento produzido nas ciências sociais, mesmo que os próprios cientistas sociais não admitam isso, e apesar da influência predominante do modelo nomológico das ciências naturais sobre as ciências sociais.

Associado a isso, Habermas constrói uma argumentação voltada a analisar o recurso à hermenêutica, em algumas formas pelas quais ela é empregada na Filosofia, apontando os limites e as possibilidades, caso ela seja utilizada para compor métodos nas ciências sociais, sobretudo pela sociologia.

E como é característica do raciocínio de Habermas, a argumentação foi constituída por meio do exame de diferentes perspectivas teóricas sobre aspectos das implicaçóes da problemática relação entre compreensão e explicação, nas ciências sociais. Na obra inteira, em todos os textos, são diversas as teorias por ele expostas e analisadas. No elenco de autores escolhidos por Habermas, encontram-se Rickert, Dilthey e Weber, com destaque para Gadamer. Mas também há análises e mençôes sobre as proposiçôes de Garfinkel, Wittgenstein, Piaget, Dewey e Cicourel, apenas para citar alguns filósofos conhecidos.

A hermenêutica é apresentada por Habermas (2009, p. 297) como uma arte de compreender que todas as pessoas desenvolvem, na medida em que conseguem obter o domínio de uma língua natural. Contudo, não é essa arte o meio adequado à construção da compreensão para ser aplicada à produção do conhecimento nas ciências sociais. 
Em relação à capacidade de compreensão inerente ao domínio linguístico, como ele mesmo denomina, Habermas busca em Gadamer a demarcação da hermenêutica filosófica. A diferença se estabelece nestes termos:

As coisas são diversas no que diz respeito à hermenêutica filosófica: ela não é uma doutrina ligada a uma arte, mas antes uma crítica. A saber, ela traz à consciência em uma postura reflexiva experiências que, no exercício de nossa competência comunicativa, ou seja, na medida em que nos movemos na linguagem, fazemos com a linguagem. (LCS, p. 297).

Ao que se pode acrescentar:

Portanto, a hermenêutica filosófica desenvolve, e minhas referências devem apenas nos lembrar disto, as intelecçōes da estrutura das línguas naturais, que podem ser conquistadas a partir de um uso refletido de uma competência comunicativa: reflexividade e objetividade são traços fundamentais da linguagem tanto quanto a criatividade e a integração da linguagem na práxis da vida. Um tal saber reflexivo que se sintetiza na "consciência hermenêutica", distingue-se evidentemente do saber-fazer que caracteriza a compreensão e o próprio discurso disciplinado. (LCS, p. 302 , grifos e aspas do autor).

Devido ao fato de consistir num exercício de interpretação com base na linguagem, as possibilidades compreensivas da hermenêutica filosófica são praticamente inesgotáveis. Tamanha plasticidade é conferida pela condição privilegiada da linguagem em acessar diretamente um sistema simbólico e a base significativa das tradiçóes, que constituem os fundamentos da metalinguagem e que, por isso mesmo, são os substratos imprescindíveis a qualquer situação de comunicação. Segundo Habermas,

[a] hermenêutica filosófica deve à arte do compreender e do tornar compreensível a experiência peculiar de que os meios de uma língua natural são por princípio suficientes para esclarecer o sentido de quaisquer contextos simbólicos, por mais estranhos e inacessíveis que eles possam ser inicialmente. A partir de qualquer língua nós podemos traduzir para qualquer língua. Nós podemos colocar em uma ligaçáo inteligível as objetivaçôes das épocas mais distantes e das culturas mais afastadas com o contexto familiar, isto é, pré-compreendido. (LCS, p. 298). 
Evidentemente, em função de sua complexidade e extensão, haveria muito mais a se destacar numa análise de A lógica das Ciências Sociais. No entanto, pelas restriçôes autoimpostas para a consecução do objetivo desta demonstração, assumem-se como suficientes os aspectos da obra acima ressaltados. Para efeitos de seguir adiante, observa-se que os assuntos tratados por Habermas em todos os textos ali reunidos apontam para a tematização original construída por Weber em torno da problemática da compreensão: a compreensão como forma adequada de identificar a base subjetiva dos fenômenos sociais, a condição da objetividade, o alcance e a validade das generalizaçôes, a complicada relação com a História e o grau de aplicabilidade do conhecimento produzido.

Em CSRCSC, escrita anos mais tarde, como foi mencionado, Habermas referiu-se à LCS, evocando-a com o objetivo de apresentar uma proposta de investigação às ciências sociais. Tal proposta seria aquela que se tornou conhecida como a perspectiva da reconstrução racional, cuja finalidade corresponde ao esforço pela explicitação dos saberes implícitos no âmbito da ação comunicativa.

Trata-se de um texto sintético, escondido entre outros textos teoricamente mais densos, mas isso não facilita a produção de uma abordagem sobre ele, muito pelo contrário. Grosso modo, as 23 páginas escritas, incluindo as notas, são usadas por Habermas para repassar o percurso conceitual elaborado em LCS, reafirmando seus principais pontos: a relação entre a compreensão, a hermenêutica filosófica e o conhecimento nas ciências sociais, a relação de estreita vinculação existente entre o exercício da compreensão e a linguagem, de modo que não há interpretação, tampouco hermenêutica, sem a mediação da linguagem, e o destaque para a perspectiva racional contida em qualquer experiência de compreensão, o que permitiria a sua objetivaçâo e uma presumível teorizaçāo.

O raciocínio adotado para a apresentação da perspectiva da reconstrução racional foi construído por Habermas em torno de quatro eixos de argumentaçáo, a começar pela elaboração de um breve balanço crítico das tendências recentes de produção científica nas ciências sociais, temporalidade esta que abrange explicitamente as décadas de 1960 e 1970, dado que o texto foi escrito em 1980.

Nessa avaliação, Habermas menciona a guinada interpretativa nas ciências sociais, na década de 1970, sublinhando que tal abordagem fora 
resultado direto do fracasso do modelo nomológico nas ciências sociais convencionais (CSRCSC, p. 38), observando ainda que os paradigmas interpretativos também se constituíram como alternativa ou resistência diante do objetivismo-positivismo e do retorno do biologismo e das explicaçóes naturalistas da sociedade e da cultura humanas (CSRCSC, p. 39).

A seguir, Habermas define o conceito de hermenêutica que será por ele empregado na sustentação da perspectiva da reconstrução racional. Nesse ponto, há a retomada da relação entre hermenêutica e linguagem, apresentada em LCS, com especial cuidado para chamar a atenção sobre o que tal relação implica, no caso de seu uso como estratégia de compreensão para a pesquisa social.

Como hermenêutica, Habermas designa a identificação do significado inerente a "[...] toda expressáo dotada de sentido - seja um proferimento (verbal ou não verbal), um artefacto qualquer como, por exemplo, um utensílio, uma instituição ou um documento". A hermenêutica pode ser aplicada a tudo isso, porque toda expressão dotada de sentido "[...] pode ser identificada, numa perspectiva bifocal, tanto como uma ocorrência observável, quanto como objetivação inteligível de um significado" (CSRCSC, p. 39).

Porém, se é possível afirmar que qualquer produto da atividade humana é dotado de sentido e, portanto, passível de uma interpretação quanto ao significado, para se alcançar a significação de algo é preciso participar de ações comunicativas. De acordo com Habermas, é apenas por meio da participaçáo, real ou imaginada em açóes comunicativas de uma comunidade linguística, que se consegue efetivamente compreender aquilo que é dito a alguém (CSRCSC, p. 40). É preciso, para tanto, possuir o domínio da linguagem:

A hermenêutica considera a linguagem, por assim dizer, em ação, a saber, da maneira como é empregada pelos participantes com o objetivo de chegar a uma compreensão conjunta de uma coisa ou de uma maneira de ver comum. (CSRCSC, p. 41, grifos do autor).

A hermenêutica apresentada contém a vinculação entre compreensão e participação numa ação comunicativa. Isso significa necessariamente a adoção da atitude performativa por aquele que pretende compreender. Por atitude performativa Habermas designa o abandono da condição de terceira pessoa (atitude objetivante) para assumir a condição de segunda (atitude conforme a regras) ou de primeira pessoa (atitude expressiva). Sobre isso, afirma Habermas: 
A atitude performativa permite a orientação mutua por pretensóes de validade (verdade, correção normativa, sinceridade) que o falante ergue na expectativa de uma tomada de posição por sim/não da parte do ouvinte. Essas pretensóes desafiam a uma avaliaçáo crítica, a fim de que o reconhecimento intersubjetivo de cada pretensão particular possa servir de fundamento a um consenso racionalmente motivado. Ao se entenderem mutuamente na atitude performativa, o falante e o ouvinte estáo envolvidos, ao mesmo tempo, naquelas funçóes que as açóes comunicativas realizam para a reprodução do mundo da vida comum. (CSRCSC, p. 42, grifo do autor).

Para que se possa de fato compreender algo, ressalta Habermas, tornase necessário que o intérprete considere a linguagem na forma pela qual ela é empregada na vida cotidiana, situação em que a utilização da linguagem se encontra apoiada em situaçôes de validez adicionais, quer dizer, num saber "[...] mais abrangente do que o saber estritamente proposicional ou relativo à verdade", que sustenta pretensóes de validez não cognitivas (CSRCSC, p. 43) e que, por isso mesmo, qualquer intérprete somente pode ter acesso a elas, mediante a participação. Nesse sentido,

[...] uma interpretação correta não é simplesmente verdadeira, como é o caso de uma proposiçáo relatando uma interpretação correta; poderse-ia antes dizer que uma interpretação correta convém a, é adequada a ou explicita o significado do interpretandum que os intérpretes devem alcançar. (CSRCSC, p. 43).

A despeito de considerar a necessária vinculação entre compreensão e participação para a consecução da perspectiva da reconstrução racional, de modo algum Habermas desconhece os riscos que tal relação apresenta para a produção do conhecimento, nas ciências sociais. É assim que se pode identificar a terceira parte da argumentação de Habermas, no texto em questão. Nesse ponto, Habermas percebe a existência de quatro prováveis dificuldades a serem enfrentadas e em torno delas avalia a viabilidade científica da utilização da hermenêutica nas ciências sociais, na forma por ele proposta.

As dificuldades indicadas por Habermas se referem às consequências da participação, a começar pela "renúncia à posição privilegiada do observador", o que implica ao intérprete assumir a condição de igualdade cognitiva derivada da condiçáo de igualdade performativa estabelecida com os demais participantes, abandonando assim a pretensão de ter algo a ensinar a eles. Se 
querem realmente compreender, por intermédio da participaçâo, os intérpretes, segundo Habermas,

[...] se vêem envolvidos nas negociaçóes sobre o sentido e a validez dos proferimentos. Ao tomarem parte em açóes comunicativas, aceitam por princípio o mesmo status daqueles cujos proferimentos querem compreender. Eles não estão mais imunes às tomadas de posição por sim/não dos sujeitos da experiência ou dos leigos, mas empenhados num processo de crítica recíproca. No quadro de um processo de entendimento mútuo - virtual ou atual - não há nada que permita decidir a priori quem tem de aprender de quem. (CSRCSC, p. 43).

Habermas aponta duas outras dificuldades, que são decorrentes da interpretação mediante participação. Há o problema da objetivação, quer dizer, "[...] de que aquilo que é compreendido numa atitude performativa deve ser traduzido naquilo que pode ser constatado do ponto de vista da terceira pessoa” (CSRCSC, p. 44). O intérprete, nesse caso, deve conseguir explicitar todos os saberes envolvidos numa açáo comunicativa, mesmo aqueles saberes de ordem náo cognitiva evocados pelos participantes para sustentar as pretensôes de validez.

Ligado a isso, há o problema da neutralidade axiológica. Por conta de sua condição de participação, o intérprete se encontra envolvido pelos mesmos saberes que sustentam as pretensões de validez não cognitivas e, sendo assim, "[...] juízos de valor se insinuam no discurso que constata fatos” (CSRCSC, p. 44).

Às dificuldades acima apontadas, Habermas acrescenta uma outra: a dificuldade de produzir saber teórico (nomologia), por meio da hermenêutica que fundamenta a perspectiva da reconstrução racional. Tal dificuldade se refere ao fato de que qualquer interpretação produzida tem como contingência os aspectos que circunscrevem a existência concreta daquilo que foi interpretado. Cada interpretação, portanto, deve ser considerada como algo tão singular como aquilo a que se dedicou a interpretar, num contexto fático. A princípio, Habermas admite que seria prudente à perspectiva da reconstrução racional também renunciar à pretensão de produzir saber teórico, e lança dúvidas sobre a possibilidade de que possa ser apresentada como alternativa de conhecimento científico às ciências sociais. Sobre isso, sintetiza Habermas:

Em suma, toda ciência que admite as objetivaçóes de significado como parte de seu domínio de objetos tem que se ocupar das consequências metodológicas do papel de participante assumido pelo intérprete, que não 
"dá" significado às coisas observadas, mas que tem, sim, de explicitar o significado "dado" de objetivaçôes que só podem ser compreendidas a partir de processos de comunicaçáo. Essas conseqüências ameaçam justamente aquela independência do contexto e aquela neutralidade axiológica que parecem necessárias para a objetividade do saber teórico. (CSRCSC, p. 44, aspas do autor).

Em relação ao problema da objetividade do conhecimento fundado na interpretação, é preciso notar que ele não se encerra na dúvida acerca da compreensáo válida, mas avança sobre o alcance ou a abrangência do conhecimento produzido por intermédio dela. O desafio para a demonstração da viabilidade do emprego da compreensão como estratégia metodológica, para as Ciências Sociais, requer a busca de solução para um provável desencontro que pode ser identificado entre a condição de racionalidade no conhecimento decorrente da interpretação em situaçóes de relacionamento específicas e a expectativa de construçáo de teorias que permitam avançar o conhecimento sobre a ação social, na perspectiva científica. Um conhecimento científico da ação social formulado mediante a compreensão deve ser suficientemente articulado, em termos lógico-conceituais, para que possa responder satisfatoriamente a quaisquer questionamentos que possam ser a ele dirigidos sobre a generalidade da explicação que pretende propor.

$\mathrm{Na}$ tentativa de encontrar uma solução para o questionamento da validade da compreensão e de sua viabilidade para produção de teoria, em CSCCSR, Habermas expóe de maneira bastante breve o esboço de um método de investigação que considera as necessidades inerentes ao esforço de interpretação e suas contingências. Trata-se da proposta da metodologia da reconstruçâo racional, cuja finalidade consiste em explicitar os conhecimentos implícitos numa ação social determinada.

Como fundamento de objetividade, Habermas salienta que todo esforço de compreensáo inevitavelmente se apoia em uma racionalidade. Para efeitos da reconstrução racional, descartam-se por completo as possibilidades de compreensão baseadas na empatia ou mesmo numa possível capacidade de descentração, em que um intérprete poderia aspirar a se transportar para a consciência do outro (CSCCSR, p. 45) e, através dessa capacidade, captar de maneira autêntica os sentidos e significados de açóes e proposiçóes. Habermas sustenta que não é possível compreender sem que essa disposição esteja sustentada em alguma pretensão de interpretação racional dos motivos 
evocados por alguém, para explicar suas escolhas e estratégias em situaçóes de relacionamento. Nessa perspectiva, enfatiza:

Em certo sentido, todas as interpretaçôes são interpretaçóes racionais. Ao compreender - e isso significa justamente: ao avaliar razóes - os intérpretes não podem deixar de recorrer a padróes de racionalidade, por conseguinte a padróes que eles próprios consideram como obrigatórios para todas as partes, inclusive para o autor e seus contemporâneos (desde que estes pudessem e se dispusessem a entrar na comunicação que os intérpretes retomam). (CSCCSR, p. 47).

Conforme já foi mencionado, a possibilidade da interpretação necessária à compreensão encontra-se vinculada à disposição de participação do intérprete numa situação de comunicação. Habermas reconhece que a participação pode comprometer de alguma forma a objetividade da observaçáo, mas destaca que apenas por meio da participaçáo os intérpretes têm acesso ao conjunto de conhecimentos evocados pelos participantes para construírem seus argumentos. $\mathrm{E}$, nesse caso, especificamente, o intérprete-participante consegue uma posição de imparcialidade negociada, porque tem acesso privilegiado à forma pela qual os demais participantes se referem à tradição para nela buscarem as razóes necessárias à composição dos proferimentos. Se, por um lado, há uma perda inevitável de objetividade devido aos riscos inerentes à participação, por ela exigir tomadas de posição em relação a valores, que requerem juízos morais, há um ganho de objetividade à medida que apenas por meio da participação se chega a alcançar a condição de autenticidade da subjetividade dos demais participantes, porque se pode compartilhar razóes dentro de contextos em que elas se tornam significativas para sujeitos em comunicaçáo.

A compreensão começa a ser formulada pelo observador-participante, quando ele tem acesso ao conjunto de conhecimentos cognitivos e não cognitivos evocados pelos falantes, em uma situação de comunicação. Nesse caso, para Habermas, o "[...] paradigma da interpretação para a hermenêutica é a interpretação de um texto da tradição” (CSCCSR, p. 46).

E, para alcançar a tradição que dá sentido aos proferimentos, Habermas indica um caminho aparentemente simples ao observador-participante. Tratase da estratégia de manifestar desconhecimento ou de provocar deliberadamente distorçóes nas condiçóes de validade em que os demais participantes apoiam seus proferimentos. Os contrastes propositadamente criados na relação entre os proferimentos e o contexto a que se referem provocam transtornos de 
comunicação. São eles que possibilitam ao observador colocar-se em outras perspectivas na situação comunicativa e, assim, esclarecer, com o auxílio dos demais participantes, os fundamentos racionais e, portanto, objetivos, mediante os quais as tradiçôes são concretamente evocadas para atribuir sentido a proposiçôes. Ou melhor, nas palavras de Habermas:

Os intérpretes parecem inicialmente compreender as frases de seu autor, mas, em seguida, fazem a experiência desconcertante de que não compreendem adequadamente o texto, isto é, não a ponto de poderem responder, se fosse o caso, a questōes do autor. Os intérpretes tomam isso como indício do fato de que continuam a referir o texto a um contexto diferente daquele em que o texto estava de fato inserido. Eles têm que rever sua compreensão. (CSCCSR, p. 46).

O intérprete-participante alcança a objetividade na compreensão, à medida que consegue identificar, nos meandros da racionalidade das proposiçóes, as razóes pelas quais

[...] o autor - na crença tácita de que determinados estados de coisas existem, de que determinados valores e normas são válidos, de que determinadas vivências podem ser atribuídas a determinados sujeitos faz em seu texto determinadas asserçóes, observa ou fere determinadas convençōes e por que dá expressão a determinadas intençôes, disposiçôes, sentimentos e coisas parecidas. (CSCCSR, p. 46).

Para Habermas, a compreensão proporciona a construção de um conhecimento diferenciado ao cientista social, desde que ele, através da participação, alcance dois níveis de entendimento sobre a situação. Um deles consiste na possibilidade de avaliar as razóes empregadas pelos falantes em suas proposições. E, caso consiga avaliar as razóes, o cientista social adquire a mobilidade de poder transportar-se para a perspectiva dos falantes, à proporção que o conhecimento das razóes the permite observar, inclusive, o leque de possibilidades simbólicas de conhecimentos cognitivos e não cognitivos, os quais estiveram disponíveis para serem escolhidos na composição de proferimentos pelos falantes. Por meio desse conhecimento, pode o intérprete observar a racionalidade dos argumentos, porque pode avaliar as escolhas feitas pelos participantes sobre a melhor forma de construí-los.

Os requisitos para atingir a compreensão, segundo Habermas, são estes: 


\begin{abstract}
Os intérpretes compreendem, pois, o significado do texto apenas na medida em que percebem por que o autor se sentia com direito a avançar determinadas asserçóes (como verdadeiras), a reconhecer determinados valores e normas (como corretos) e a exprimir determinadas vivências (como sinceras) (ou, conforme o caso, a atribuí-las a outrem). Os intérpretes têm de aclarar o contexto a que o autor manifestamente não pode deixar de pressupor como o saber compartilhado pelo público contemporâneo dele... (CSCCSR, p. 46).
\end{abstract}

Habermas defende sua proposta de investigação social baseada na interpretação, ressaltando que a perspectiva da reconstruçâo racional pode ser uma alternativa metodológica viável às ciências sociais, por se constituir numa forma de conhecimento que contém três qualidades. A perspectiva da reconstrução racional proporciona ao cientista produzir um saber sobre as ações ao mesmo tempo crítico, construtivo e teórico.

Para Habermas, a condição crítica da reconstrução racional deriva do fato de que "[...] as reconstruçôes racionais explicitam as condiçôes de validade de proferimentos" e, por isso, "[...] elas também podem explicar casos desviantes" (CSCCSR, p. 48).

Quanto à condição construtiva, ela está ligada à potencialidade da reconstrução racional de "[...] fixar novos padróes analíticos", à medida que "[...] as reconstruçóes racionais empurram as diferenciaçóes entre as pretensóes de validez particulares para além dos limites que a tradição ensinou" (CSCCSR, p. 48).

Em relação à teoria produzida através da reconstrução racional, Habermas entende que seja possível produzir um "[...] saber teórico competitivo" (grifo do autor), desde que haja "[...] sucesso na análise de condiçóes de validez muito gerais". Nesse caso, "[...] as reconstruçôes racionais poderão surgir com a pretensão de descrever universais” (CSCCSR, p. 48).

No entanto, a capacidade de produção teórica não deve entusiasmar demasiadamente os cientistas sociais que buscam alternativas metodológicas viáveis. Habermas aponta para a precaução quanto à probabilidade de que as potencialidades apresentadas na perspectiva da reconstrução racional venham a contribuir, igualmente elas, para a produção de conhecimentos distorcidos sobre as ações sociais, e que inevitavelmente são expostos na forma de "fundamentações últimas" (CSCCSR, p. 48). Antes de tudo, é preciso que o cientista social admita a condição de falibilidade inerente a todo tipo de conhecimento humano, 
devido ao fato de que todo conhecimento será sempre tributário e envolvido por alguma subjetividade. A advertência se faz nestes termos:

\begin{abstract}
Por isso, é importante ver que todas as reconstruçóes racionais, assim como os demais tipos de saber só têm um status hipotético. Pois é sempre possível que elas se apóiem numa escolha errônea de exemplos; elas podem obscurecer e distorcer intuiçóes corretas e, o que é mais freqüente ainda, generalizar excessivamente casos particulares. (CSCCSR, p. 49, grifo do autor).
\end{abstract}

\title{
3 - A pretexto de algumas conclusóes
}

Quando comparadas as concepçóes de compreensão presentes nas teorias de Weber e Habermas, logo de início há que se ressaltar que ambos, tanto Weber quanto Habermas, identificam a complicada relação da Sociologia e das Ciências sociais com os fatores contextuais da ação humana. Em última instância, toda ação humana está sempre vinculada à história e à cultura, e estes são os maiores obstáculos existentes na produção de um saber que pretenda a abrangência explicativa na forma de um saber teórico. Devido às suas próprias características, a história e a cultura devem ser consideradas como objetos de conhecimento invenciveis.

A comparaçáo entre as teorias permite observar ainda que Weber não aprofundou o problema da interpretação no método compreensivo, não explorando a relação entre interpretação e participação, embora considerasse que qualquer compreensão depende do exercício de interpretação, e tivesse a pretensão de, como Habermas, conseguir produzir uma teoria da ação orientada pela subjetividade e motivada empiricamente, como se pode verificar pela disposição de Weber em identificar a presença causal dos tipos ideais nos macroprocessos históricos.

É oportuno enfatizar que tanto Weber quanto Habermas advertem para condição de permanente incerteza que envolve o conhecimento nas ciências sociais, a qual se deve à influência inevitável da subjetividade do cientista num processo de conhecimento que está condicionado à interpretação. Nas concepçóes de compreensão de ambos, nota-se a recomendação explícita de que o cientista deve se admitir também como sujeito histórico na construção de interpretaçóes sobre ação de outros sujeitos e, portanto, igualmente subordinado às contingências individuais e culturais que cercam qualquer conhecimento e que são próprias de seu tempo e lugar. 
Apesar desses pontos em comum, na teoria de Weber constata-se a aposta na subjetividade do cientista para delimitar racionalmente um objeto e envolvê-lo por um método cuja lógica possa ser demonstrada objetivamente. Nesse caso, a objetividade seria, em última instância, tributária do grau de convicção do cientista em alcançar a necessária neutralidade axiológica no conhecimento que se dedica a produzir. Para Habermas, no entanto, a condição de objetividade é alcançada mediante a participação do cientista nas situaçóes que pretende investigar. A objetividade adviria do acesso que o cientista pode ter à racionalidade que envolve e é inerente a toda açáo comunicativa. Todavia, a falibilidade ainda continua sendo uma contingência do conhecimento, e deve ser assumida como risco calculado, à medida que o esforço objetivo pela interpretaçáo, em todo o processo de conhecimento, depende de disposiçôes subjetivas, desde a decisão pela participação numa determinada ação comunicativa até terminar na identificação e avaliação das racionalidades presentes em todas as situaçóes de comunicaçáo.

Por fim, a despeito do esforço notável de Weber e Habermas em refletir criticamente sobre as nuances peculiares do processo de produção de conhecimento, nas Ciências Sociais, na tentativa de identificar as limitações na elaboração de teorias sobre os fenômenos da vida social humana com fundamentos de validade, fica claro que muitas questóes continuam em aberto, sobretudo aquelas clássicas, relacionadas ao grau de aplicabilidade. Isso se refere diretamente à possibilidade e às condições segundo as quais o saber científico construído nas Ciências Sociais venha a ser empregado de alguma forma na resolução de problemas da vida, do mesmo modo como são utilizados os conhecimentos das ciências convencionais. 
POKER, José Geraldo A. B. The meanings of understanding in the theories of Weber and Habermas. Trans/Form/Ação, Marília, v. 36, p. 221-244, 2013. Edição Especial.

\begin{abstract}
Assuming that the social theory developed by Habermas is very similar to that constructed by M. Weber, this article performs a comparative study with the intention of identifying the ways in which Weber and Habermas built the concept of understanding. Both authors chose this concept, each in his own way, as a methodological tool appropriate to the difficulties of the production of scientific knowledge in the social sciences. As much for Weber as for Habermas, knowledge in the social sciences cannot escape the direct influences of the subjectivity of the scientist, as it also cannot protect itself from the historical and cultural contingencies to which every human action is inevitably linked. Therefore, based on their own reasons, both Weber and Habermas point to understanding as the possible form of knowledge, which implies the renunciation of the explanatory pretensions and general theories of ultimate foundations typical of the conventional sciences.
\end{abstract}

KEYWORDS: Understanding. Explanation. Social Sciences. Habermas. Weber.

\title{
REFERÊNCIAS
}

HABERMAS, J. Ciências Sociais reconstrutivas versus Ciências Sociais Compreensivas. In: Consciência moral e agir comunicativo. Rio de Janeiro: Tempo Brasileiro, 1989. (CSCCSR). . A lógica das Ciências Sociais. Petrópolis-RJ: Vozes, 2009. (LCS).

SCHLUCHTER, W. A neutralidade de valor e a ética da responsabilidade. In: COELHO, M.F.; BANDEIRA, L.; MENEZES, M. L. (Org.). Politica, ciência e cultura em Max Weber. Brasília: UnB, 2000.

WEBER, M. A objetividade do conhecimento na ciência social e na ciência política. In: Ensaios sobre a teoria das Ciências Sociais. Tradução de Rubens Eduardo Frias. 3. ed. São Paulo: Centauro, 2008b.

. A "objetividade" do conhecimento nas ciências sociais. Tradução de Gabriel Cohn. São Paulo: Ática, 2006.

. Conceitos básicos de Sociologia. 5. ed. São Paulo: Centauro, 2008a.

. Economía y sociedad. México: Fondo de Cultura, 1997. 
POKER, J. G. A. B. 